\section{Questión}

Periodismo / Comunicación ISSN 1669-6581
- Av. $44 \mathrm{~N}^{\circ} 676,1^{\circ} \mathrm{piso}$

CP 1900 - La Plata - Argentina

(i) www.perio.unlp.edu.ar/question

Un aporte para el debate sobre la educación y la experiencia de virtualización a las que nos empujó el aislamiento social obligatorio

Pablo Quiroga

https://doi.org/10.24215/16696581e383

\title{
Un aporte para el debate sobre la educación y la experiencia de virtualización a las que nos empujó el aislamiento social obligatorio.
}

\section{A contribution to the debate on education and the virtualization experience to which we were pushed by mandatory social isolation.}

Pablo Quiroga

pqbcaj@gmail.com

Reseña del 1er. conversatorio 2020 organizado por el Laboratorio de Investigación en Comunicación Visual (LICoV). Unidad de investigación de la Facultad de Artes de la UNLP.

Bajo el título "La enseñanza en disciplinas proyectuales y los avatares de la adecuación a contextos de educación a distancia", se llevó adelante el primero de un ciclo de conversatorios organizados por el LICoV; del que participaron las diseñadoras en comunicación visual: Silvia Andrea Cristian Ladaga, Ana Cuenya, Julia Gouffier y Marina Calderone.

Disponible en: https://youtu.be/wB8_3e3cZAE

El eje de la discusión, circuló en torno a la experiencia -incipiente en la mayoría de los casos-, de adecuacionrd a la modalidad a distancia, para la enseñanza de las disciplinas proyectuales y en particular el diseño en comunicación visual.

En estas últimas semanas, la Universidad se ha visto atravesada por la inevitable necesidad de sostener los espacios educativos y de formación, ante las acciones preventivas por la pandemia 
de Covid19 declarada a nivel mundial. Este tema ha motivado reflexiones que, si bien pueden anclarse en la coyuntura citada, vienen siendo ademas un espacio de vacancia dentro del campo del diseño, tanto en la aplicación de procesos educativos de carácter no presencial -por ser disciplinas tan fuertemente ligadas al hacer práctico-, como en la sistematización de debates respecto de las posibilidades de desarrollo de estas modalidades en la enseñanza de sus ámbitos disciplinares.

Desde distintos espacios dedicados al trabajo e investigación sobre la educación a distancia, es usual encontrar planteos en relación a las posibilidades que la educación en línea ofrece, respecto del seguimiento y registro del proceso, así como la vasta oferta de herramientas que permiten una interactividad en la articulación de dinámicas con diferentes temporalidades (sincrónicas y asincrónicas). En ese sentido "Cris" Ladaga habló de ciertas ventajas en el área del Diseño, dadas por la proximidad de la profesión al uso de la tecnología; esa cuestión según reconoce, es un punto a favor para el aprendizaje en tiempos de pandemia. Hay una relación con lo tecnológico desde el diseño, que da un buen piso de alfabetización digital. Lo que seguiría entonces, tiene que ver con trabajar en lo didáctico y pedagógico. Reflexionar sobre cómo la educación en la virtualidad tiene sus particularidades. Reconoce, claro, que existen como en toda situación nueva y que surge de la crisis, ciertas dificultades y resistencias. Parafraseando a $\mathrm{N}$. Chávez, deja entrever cierta solución pragmática con la idea de que una vez puestos a pensar, hay que avanzar y vencer el miedo.

Por su parte, Ana Cuenya, comentó la experiencia desarrollada en la Cátedra B de Diseño en Comunicación Visual de la FdA UNLP, en la que vienen trabajando la educación en línea desde hace más de un año, aplicado a quinto año que es el curso de trabajo de tesis. Esta es una experiencia previa bastante novedosa en el ámbito de la enseñanza en Diseño y es a partir de ella que, ante esta pandemia, la Cátedra de la que ella es Titular, avanzó en el proceso de extender la oferta en línea para segundo, tercero y cuarto año.

Cuenya, destaca la posibilidad de transparentamiento -si se permite el neologismo- del aula virtual. Dice que esto permite probar y revisar materiales para la puesta en común, así como para la evaluación, de un modo muy dinámico y acertado. Habla además del marco teórico de todo lo que implica el diseño de contenidos en línea y su accesibilidad, destacando la importancia de producir materiales a medida para que no se conviertan en listados inacabables. Explica el modo en que los procesos de evaluación que aplican en las plataformas colaborativas, permiten 
explorar los proyectos de compañeros de cursada, aportando sobre cuáles han sido las trayectorias y los registros de esos recorridos, propios y de Ixs demás.

Julia Goufler comentó sobre la importancia de que en las dinámicas de trabajo en línea, se fortalezca la relación docente-alumnx, así como entre estudiantes. Para ella, es central pensar el modo en que lo técnico (muchas veces inclusive en lo presencial) imprime cierta distancia en la relación educativa, en donde quien se encuentra en el rol de alumnx, muchas veces se siente muy solitarix; por eso es importante que el/la/le docente esté presente y fortalezca un buen vínculo, aunque sea a través de lo escrito que es el eje de diálogo más habitual que se establece en línea, pero que también puede ser sensible a las necesidades subjetivas, para intentar tener un diálogo lo más cercano posiblei. Esto llevaría a pensar un nuevo rol docente en la virtualidad, que se mueva hacia líneas pedagógicas que recuperen los lazos de comunicación en la educación a distancia, que permitan establecer un compromiso y una construcción de conocimiento efectivos.

Marina Calderone, se refirió a cómo la urgencia del aislamiento social preventivo y obligatorio nos colocó en un lugar ante el cual fue imperioso llevar la educación presencial mediante la mediación tecnológica y el uso de las tics. Partiendo de la conciencia de que "hemos sido formados como docentes y Ixs alumnxs se inscribieron, para compartir en un aula y poder trabajar la construcción del conocimiento de modo presencial". Entonces toda esta situación nos pone ante la pregunta de qué enseñar y con qué herramientas. El/la/le estudiante necesita al docente de modo sincrónico y asincrónico, como presencia, porque no eligieron la modalidad de cursada a distancia. Ella destaca que cada crisis ofrece una oportunidad.

El 2020 lo recordaremos como el año en el que aprendimos intensamente a trabajar en lo digital.

\section{Nota}

\footnotetext{
i Además de la palabra escrita, podemos sumarle gestualidad, hacer comentarios de audio sobre la producción, podemos utilizar los foros y demás, pero siempre es importante chequear que las herramientas cumplan la función para la que fueron pensadas
} 